\title{
NÍVEIS CRÍTICOS DE POTÁSSIO PARA A SOJ A EM LATOSSOLO HÚMICO DE SANTA CATARINA(1)
}

\author{
E.E. SCHERER ${ }^{(2)}$
}

\begin{abstract}
RESUMO
Visando avaliar a resposta da soja à adubação potássica e estabelecer níveis críticos do nutriente no solo e na planta, foi desenvolvi do um experimento de campo, por doze anos consecutivos, em um Latossolo Húmico distrófico, no município de Campos Novos (SC). Os tratamentos consistiram de quatro doses de adubo potássico, aplicadas antes do primei ro cultivo, em combinação com três doses de $K$, aplicadas anualmente, a partir do quinto ano. Definiu-se o nível crítico do nutriente no solo e na planta, tomando como base a produção relativa de $90 \%$ Os teores de $\mathrm{K}$ do solo correlacionaram-se, significativamente, com a concentração de $K$ na folha e com o rendimento de grãos, revelando-se adequados na predição da disponi bilidade de $K$ para as plantas. Os níveis críticos de $\mathrm{K}$ no solo e na folha foram de $63 \mathrm{mg} \mathrm{dm}^{-3}$ e $14 \mathrm{~g} \mathrm{~kg}^{-1}$, respectivamente. Foram estabelecidas quatro classes de teores de $\mathrm{K}$ no solo e no tecido foliar: muito baixo, quando menor que $38 \mathrm{mg} \mathrm{dm}^{-3}$, no solo, e $9 \mathrm{~g} \mathrm{~kg}^{-1}$, na fol ha; baixo, quando entre $39 \mathrm{e}^{4} \mathrm{mg} \mathrm{dm}^{-3}$, no solo, e $9 \mathrm{e} 12 \mathrm{~g} \mathrm{~kg}^{-1}$, na fol ha; médio,

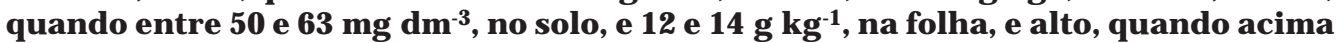
de $63 \mathrm{mg} \mathrm{dm}^{-3}$, no solo, e acima de $14 \mathrm{~g} \mathrm{~kg}^{-1}$, na folha. A redução na disponibilidade do $\mathrm{K}$, no solo e na concentração na folha, acarretou maior absorção de Mg pelas plantas com conseqüente redução na relação $\mathrm{K} / \mathrm{Mg}$ na folha.
\end{abstract}

Termos de indexação: Glycine max (L.) Merrill, potássio disponível, K na folha, sintomas de deficiência.

\section{SUMMARY: POTASSIUM CRITICAL LEVELS FOR SOYBEAN ON A HAPLOHUMOX SOIL IN SANTA CATARINA}

\begin{abstract}
Soybean response to potassium fertilization was evaluated over a twelve-year period in a field experiment on a Haplohumox soil, in Campos Novos, State of Santa Catarina, Brazil. Treatments consisted of a combination of four levels of $\mathrm{K}_{2} \mathrm{O}$ applied in the first year $(0,80,160$ and $\left.320 \mathrm{~kg} \mathrm{ha}^{-1}\right)$, and threelevels of $\mathrm{K}_{2} \mathrm{O}\left(0,40\right.$ and $\left.80 \mathrm{~kg} \mathrm{ha}^{-1}\right)$ applied annually from the fifth year. The critical level of $K$ in the soil and in the leaves was determined based on the $K$ concentration responsiblefor $90 \%$ of thesoybean yield. Potassium in thesoil was highly correlated with yield and $\mathrm{K}$ concentration in the leaves, and may be a suitable procedure to predict the availability of $K$ to the plants. The critical leve of $K$ in thesoil was $63 \mathrm{mg} \mathrm{dm}^{-3}$ of $K$, and in the
\end{abstract}

\footnotetext{
(1) Recebido para publicação em fevereiro de 1997 e aprovado em novembro de 1997.

(2) Pesquisador da EPAGRI-Centro de Pesquisa para Pequenas Propriedades (CPPP). Caixa Postal 791, CEP 89801-970 Chapecó (SC).
} 


\begin{abstract}
leaves at flowering it was $14 \mathrm{~g} \mathrm{~kg}^{-1}$. Normal leaves, with no visual symptoms, had K concentrations from 12 to $19 \mathrm{~g} \mathrm{~kg}^{-1}$. A decrease in the soil $\mathrm{K}$ supplying capacity increased $\mathrm{Mg}$ concentration and decreased $\mathrm{K} / \mathrm{Mg}$ ratio in the leaves. Four classes of $\mathrm{K}$ content in the soil and in the leaf tissueweredefined: very low, when $\mathrm{K}$ concentration was bel ow $38 \mathrm{mg} \mathrm{dm}^{-3}$ in thesoil and bel ow $9 \mathrm{~g} \mathrm{~kg}^{-1}$ in the leaves; low, when between 39 and $49 \mathrm{mg} \mathrm{dm}^{-3}$ in the soil, and between 9 and $12 \mathrm{~g} \mathrm{~kg}^{-1}$ in the leaves; medium, when between 50 and $63 \mathrm{mg} \mathrm{dm}^{-3}$ in the soil and between 12 and $14 \mathrm{~g} \mathrm{~kg}^{-1}$ in the leaves; high, when higher than $63 \mathrm{mg} \mathrm{dm}^{3}$ in the soil, and higher than $14 \mathrm{~g} \mathrm{~kg}^{-1}$ in the leaves.
\end{abstract}

Index terms: Glycine max (L.) Merrill, potassium availability, K in leaf, deficiency symptoms.

\section{INTRODUÇÃO}

Estudos de calibração com potássio, com vistas em definir critérios mais adequados dentro de um programa de adubação, poderão ser mais bem compreendidos se houver um acompanhamento da dinâmica do elemento no sol o e da resposta da cultura no decorrer de vários cultivos.

Em geral, a literatura relata poucos trabal hos de pesquisa com adubação potássica desenvolvidos por um período superior a três anos (Ben, 1981). Poucos, também, são os casos com respostas positivas à adubação potássica, nos primeiros anos de cultivo, e, quando ocorrem, são, em geral, de pequena magnitude (Voll \& Bays, 1976; Ben, 1981; Scherer et al., 1982; Siqueira, 1982). Todavia, muitos desses solos, em que não há resposta a $\mathrm{K}$ nos primeiros anos de cultivo, apresentam alta predisposi ção ao esgotamento desse el emento, podendo o mesmo ocorrer em curto período de tempo, quando não houver adequada reposição do nutriente pela adubação (Miel niczuk \& Sel bach, 1978; Siqueira, 1982).

Para os solos dos estados do Rio Grande do Sul e de Santa Catarina, a Comissão de Fertilidade do Solo (1995) definiu o nível crítico de K-extraível pelo método Mehlich-1 em $80 \mathrm{mg} \mathrm{dm}^{-3}$. Alguns trabal hos têm mostrado que, quando os teores de K-extraível no solo estão acima de $60 \mathrm{mg} \mathrm{dm}^{-3}$, as respostas da soja à aplicação deK são, em geral, pouco expressivas (Ben, 1981), concordando com o nível critico estabelecido para os solos do Estado de São Paulo (Raij, 1991). Borkert et al. (1993a) estabel eceram um nível crítico de $40 \mathrm{mg} \mathrm{kg}^{-1}$ para um latossolo de textura argi losa do Estado do Paraná, enquanto Souza (1984) estabeleceu um nível crítico de $50 \mathrm{mg} \mathrm{kg}^{-1}$ de Kdisponível para um latossolo argiloso de cerrado do Brasil Central. Assim, fica caracterizado que o nível crítico de K no solo pode variar grandementede acordo com as condições de solo e local.

Para acompanhar as relações desse elemento no sistema solo-planta e avaliar o estado nutricional das plantas, a determinação dos teores na planta podeser recomendável. Nesse caso, o método mais utilizado é a diagnose foliar. Porém, dadas as dificuldades na inter pretação dos resultados, principalmente no que se refere ao estabelecimento de níveis críticos, esse método sofre restrições.
As informações sobre diagnose foliar e níveis críticos de K no tecido de soja no Brasil ainda são escassas. Bataglia \& Dechen (1986) definiram como nível crítico para a soja uma concentração de $17 \mathrm{~g} \mathrm{~kg}^{-1}$ no tecido fol iar. Malavol ta et al. (1989) estabel eceram, como ideal para o ótimo desenvol vimento da cultura, concentrações entre 17 e $25 \mathrm{~g} \mathrm{~kg}^{-1}$ de $\mathrm{K}$ na folha, o que foi confirmado por Borkert et al. (1993b). Esses autores constataram deficiências severas de $\mathrm{K}$ nas plantas, quando os teores estavam abaixo de $12 \mathrm{~g} \mathrm{~kg}^{-1}$.

Segundo Mascarenhas et al. (1980), para cada tonelada de grãos de soja produzida há uma retirada de $18 \mathrm{~kg}$ de $\mathrm{K}$ do solo. Dessa forma, à medida que $\mathrm{a}$ agricultura se intensifica e as produtividades aumentam, verifica-se uma importância crescente da adubação potássica, sendo necessário definir padrões seguros para quantificar as necessidades de adubação da cultura da soja.

Fatores de solo, clima, planta (Bataglia \& Dechen, 1986), além de interações com outros nutrientes, podem interferir na absorção e acúmulo de $\mathrm{K}$ pelas plantas (Rosolem, 1982). Alterações na absorção de K em função da disponibilidade de $\mathrm{Ca}$ e de $\mathrm{Mg}$ no solo são bastante freqüentes e foram observadas por diversos autores (Omar \& EI K obbia, 1966; Rosolem, 1982; Mascarenhas et al ., 1988). Os autores relataram quea maior disponibilidade desses dois cátions no solo afeta a absorção de $K$, diminuindo as suas concentrações no tecido das plantas.

Este trabalho teve como objetivo determinar os níveis críticos de $\mathrm{K}$ no solo e no tecido foliar da soja, bem como relacioná-los com a absorção de outros nutrientes.

\section{MATERIAL E MÉTODOS}

O experimento que serviu de base para este estudo foi desenvolvido no município de Campos Novos (SC), com doze cultivos consecutivos de soja, em Latossolo Húmico distrófico com $69 \%$ de argila e boa disponibilidade de K (125 mg dm-3$)$. Foram avaliados e analisados dados de rendimento de grãos e teores de $\mathrm{K}$ no solo e na planta. Maiores detalhes sobre a condução do experimento, seqüência de culturas e procedimentos adotados na coleta e avaliação dos dados encontram-se em Scherer (1998). 
Para determinar o teor de $\mathrm{K}$ do solo, foram col etadas amostras na camada arável de 0-20 cm, após cada col heita de soja, em número de 20 subamostras por unidade experimental. As amostras foram secas em estufa a $40^{\circ} \mathrm{C}$, moídas e peneiradas em peneira de $2 \mathrm{~mm}$ e, a seguir, anal isadas pel o método Mehlich-1, conforme método da ComissãodeFertilidadedoSoloRS/SC (1995).

Além da observação visual dos sintomas de deficiência, foram col etadas amostras para diagnose foliar. As amostras, num total de 20 subamostras por parcela, foram col hidas no período do florescimento, tomando-se as terceiras fol has a partir do ápice das plantas. As fol has foram lavadas, secas em estufa a $65^{\circ} \mathrm{C}$ e moídas para análise. A digestão das amostras foi feita por via úmida, seguindo método descrito por Tedesco et al. (1982).

As produções de grãos de soja, avaliadas anual mente, foram ajustadas para $13 \%$ de umidade. O nível crítico para $\mathrm{K}$ foi obtido pelo cálculo do teor do elemento no solo ou na planta necessário para promover $90 \%$ da produção máxima.

Os resultados foram submetidos a análises de variância, regressão e correlação. As relações entre as características da planta (Y) eas do solo (X) foram testadas mediante modelos de regressão linear e curvilinear, transformando-se as produções de grãos decada ano em val ores rel ativos com base na produção máxima de cada ano (100\%).

\section{RESULTADOS E DISCUSSÃO}

Utilizando os rendimentos relativos, calculados anualmente para os doze cultivos sucessivos de soja, elaborou-se a curva de calibração do K-disponível no solo determinado pelo método Mehlich-1 (Figura 1). O coeficiente de determinação $\left(R^{2}\right)$ de 0,82 foi altamente significativo.

Definindo como nível crítico o valor de $\mathrm{K}$ do solo no qual ocorre uma redução no rendimento de, no máximo, $10 \%$, esse val or foi de $63 \mathrm{mg} \mathrm{dm}^{-3}$. Esse val or é inferior ao atual nível crítico ( $\left.80 \mathrm{mg} \mathrm{dm}^{-3}\right)$, definido pela Comissão de Fertilidade do Solo (1995) para os solos de Santa Catarina e Rio Grande do Sul, porém está bastante próximo ao nível crítico de $60 \mathrm{mg} \mathrm{kg}^{-1}$ deK, estabelecido para os solos doEstado deSãoPaulo (Raij, 1991). Observa-seser essevalor superior aos níveis críticos de 40 e $50 \mathrm{mg} \mathrm{kg}^{-1}$, definidos por Borkert et al. (1993a), para um Latossol o Roxo do Estado do Paraná, e por Souza (1984), para um latossolo de cerrado do Brasil Central, respectivamente.

Pela curva ajustada, pode-se estabel ecer uma faixa de suficiência para altas produções, variando de $60 \mathrm{a}$ $80 \mathrm{mg} \mathrm{dm}^{-3}$ de $\mathrm{K}$ no solo, acima da qual as probabilidades de resposta à adubação potássica são mínimas ou são pouco expressivas (menos de 5\%). Contudo, a máxima resposta da cultura, determinada pela função ajustada, somente foi atingida com $122 \mathrm{mg} \mathrm{dm}^{-3}$ de $\mathrm{K}$ no solo, concordando com o limite superior estabelecido por Raij (1991).

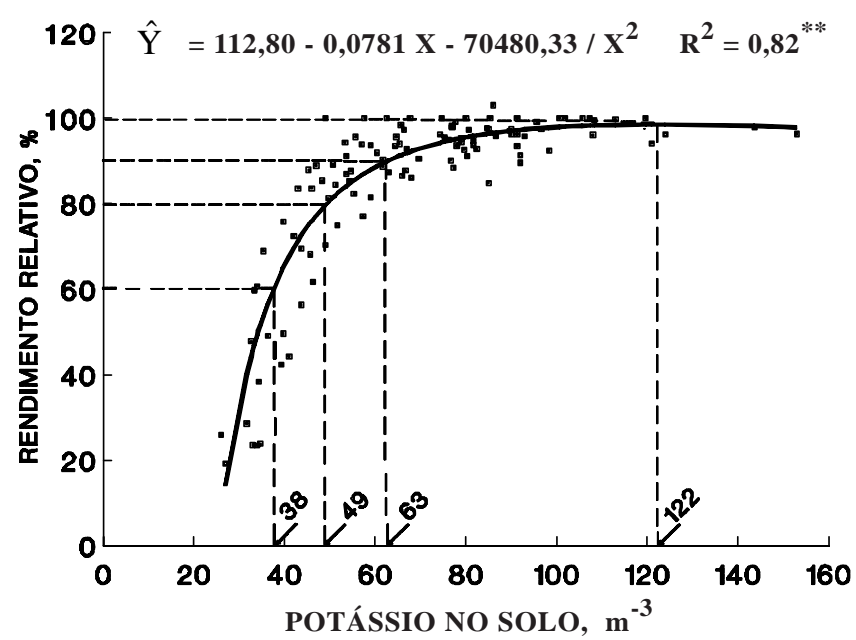

Figura 1. Rendimento relativo de soja em função do teor de potássio disponível no solo. Resultado de doze safras. Média de três repetições.

Os dados da figura 1 indicam, ainda, que, para atingir $80 \%$ do rendimento máximo, um teor mínimo de, aproximadamente, $50 \mathrm{mg} \mathrm{dm}^{-3}$ de $\mathrm{K}$ no solo foi suficiente, porém qual quer decréscimo nesseteor pode acarretar grandes decréscimos na produção, se a cultura não for adubada com esse nutriente. I sso pode ser atribuído ao pequeno intervalo entre o nível de K no sol o ondea soja atinge $80 \%$ do rendimento máximo ( $50 \mathrm{mg} \mathrm{dm}^{-3}$ ) e aquele em que o rendimento cai para $30 \%$ (30 $\left.\mathrm{mg} \mathrm{dm}^{-3}\right)$. A simples redução de 50 para $30 \mathrm{mg} \mathrm{dm}^{-3}$ de $\mathrm{K}$ do solo propiciou uma redução de $50 \%$ no rendimento de grãos. Resposta semelhante foi observada por Borkert et al. (1993a) em solo argil oso do Estado do Paraná.

Essa redução no teor de $K$ do solo, porém, não acontece de uma safra para outra (Scherer, 1998), podendo ser corrigida com acompanhamento periódico dos teores do el emento no sol o, o que, normalmente, é feito pelo produtor.

Embora, neste trabalho, não tenha sido determinado oteor deK não-trocável, presume-se que sua contribuição tenha sido expressiva, influenciando a resposta da cultura, principalmente nos últimos cultivos, nos tratamentos com teores de K-disponível abaixo do nível crítico. Trabal hos desenvolvidos por Rosolem et al. (1988) eFernandes et al. (1993) revelam que, em sol os com baixos teores de K-trocável, a soja pode aproveitar boa parte do nutriente de formas nãotrocáveis. Porém, como a liberação do K dessas formas é relativamente lenta, sempre há prejuízos na produtividade, quando a cultura não for devidamente adubada com esse nutriente (Rosolem et al., 1988).

Com base na resposta obtida (F igura 1 ), foi possível estabelecer quatro dasses deteores de $\mathrm{K}$ no sol o: muito baixo, quando menor que $38 \mathrm{mg} \mathrm{dm}^{-3}$, com rendimentos inferiores a $60 \%$ do teto máximo; baixo, entre 39 e $49 \mathrm{mg} \mathrm{dm}^{-3}$, com rendimentos entre 60 e $80 \%$ do teto máximo; médio, entre 50 e $63 \mathrm{mg} \mathrm{dm}^{-3}$, com rendimentos entre 80 e $90 \%$ do teto máximo; alto, acima de $63 \mathrm{mg} \mathrm{dm}^{-3}$, com rendimentos superiores a 
90\% do teto máximo. O intervalo entre 60 e $80 \mathrm{mg} \mathrm{dm}^{-3}$ de K-disponível caracteriza uma faixa de suficiência, acima da qual a probabilidade de resposta à adubação potássica é pequena, não havendo necessidade de adubar com $\mathrm{K}$.

Com a sucessão de cultivos e exaustão do $K$ do solo pela extração das culturas, verificou-se grande redução na concentração de $K$ no tecido foliar, com reflexos na produção de grãos. Com os resultados de anál ise fol iar das amostras das quatroúltimas safras, obteve-se bom ajustamento nas equações de regressão entre teor de $\mathrm{K}$ no tecido foliar e teor de K-extraível do solo $\left(R^{2}=0,93^{* *}\right)$ e, com a utilização dos dados de produção de grãos em valores relativos, rendimento relativo, também entre estes e o teor de $K$-foliar $\left(R^{2}=0,93^{* *}\right)$ (Figuras 2 e 3 ).

Observa-sena figura 2, que os teores de $\mathrm{K}$ no tecido foliar da planta foram significativamente afetados pela disponibilidade do nutriente no sol o. O coeficiente de determinação ( $R^{2}$ ) indica que $93 \%$ da variação do teor deK na fol ha pode ser atribuída à variação do teor de $\mathrm{K}$ do solo.

Utilizando os rendimentos relativos e os teores de $\mathrm{K}$-foliar das últimas quatro safras de soja, ajustou-se a curva de calibração para definição dos níveis de suficiência na fol ha por ocasião do florescimento das plantas (Figura 3). Os dados mostram que com $14 \mathrm{mg} \mathrm{kg}^{-1}$ de $\mathrm{K}$-foliar foi conseguido $90 \%$ do rendimento máximo, sendo o nível $100 \%$ obtido a partir de $19 \mathrm{mg} \mathrm{kg}^{-1}$ de $\mathrm{K}$ no tecido foliar.

Na prática, porém, é muito difícil fixar um teor exato que possa ser considerado como nível crítico do nutriente na planta, uma vez que o valor pode ser influenciado por níveis de outros elementos, pelas características intrínsecas do cultivar e por fatores de solo e clima (Bataglia \& Dechen 1986; Borkert et al., 1993b). Por isso, convém optar por faixa ou área crítica, como sugeriram Bataglia \& Dechen (1986).

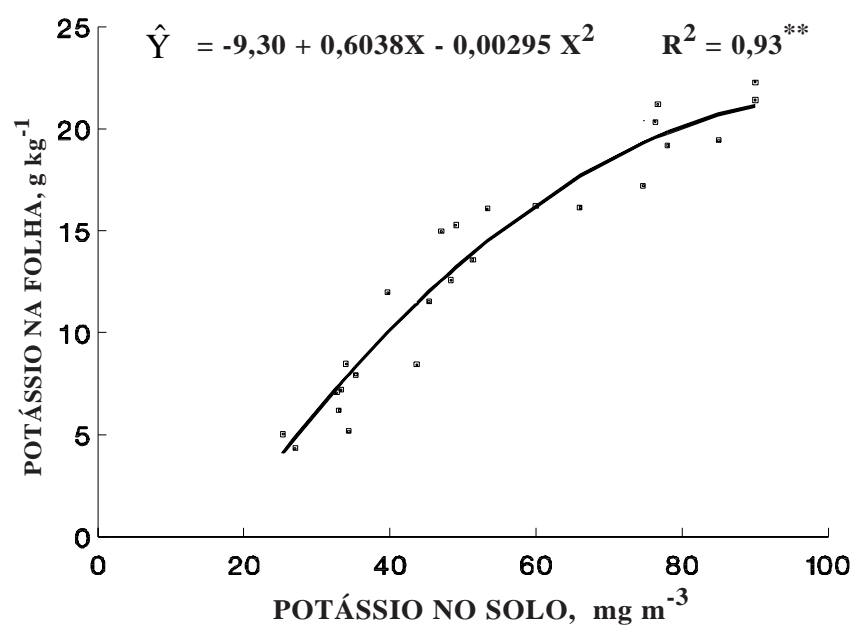

Figura 2. Teor médio de potássio no tecido foliar de soja em função do teor do nutriente no solo. Resultado de quatro safras. Média de três repetições.

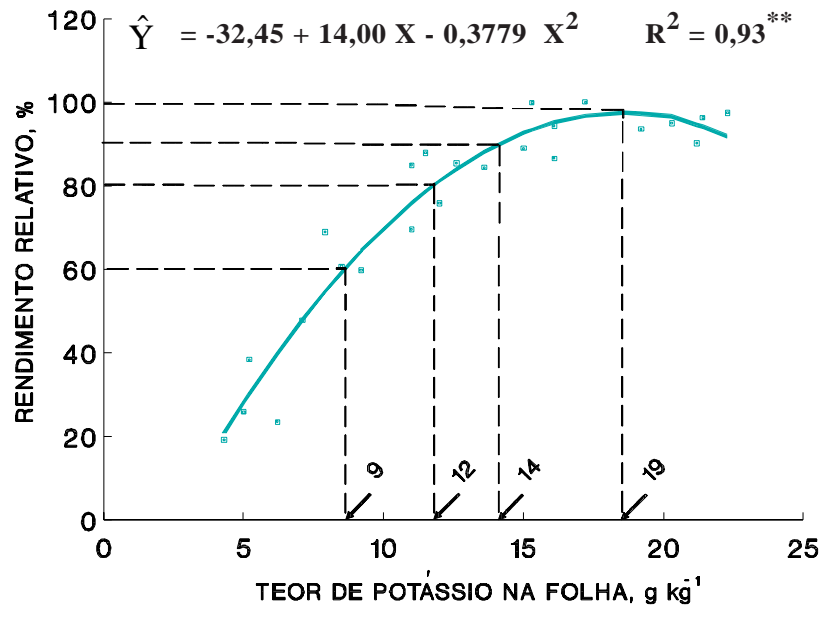

Figura 3. Rendimento relativo de soja em função do teor de potássio no tecido foliar. Resultado de quatro safras. Média de três repetições.

Deficiências severas de $K$ nas plantas somente foram observadas com teores de K-foliar inferiores a $9 \mathrm{~g} \mathrm{~kg}^{-1}$. Com teores de K-foliar na faixa de 9 a $12 \mathrm{~g} \mathrm{~kg}^{-1}$, os sintomas de deficiência também foram visíveis, mas se restringiram ao aparecimento de manchas cloróticas e necroses nas bordas das fol has mais vel has. Com teores deK-fol iar na faixa intermediária, as produtividades variaram entre 60 e $80 \%$ do rendimento máximo. Quando os teores estavam acima de $12 \mathrm{~g} \mathrm{~kg}^{-1}$, suficientes para atingir uma produtividade acima de $80 \%$ da máxima esperada, foi observada a "fome oculta", ou seja, redução na produção de grãos, com crescimento normal das plantas, sem sintomas visuais de deficiência, concordando com as observações feitas por Borkert et al. (1993b).

Limitações drásticas no crescimento das plantase na produção de grãos ocorreram, quando os valores de $\mathrm{K}$-foliar se aproximaram de $5 \mathrm{~g} \mathrm{~kg}^{-1}$, acarretando, nessa situação, maior abortamento deflores e vagens, retardamento das brotações e morte da gema apical das plantas. Mascarenhas et al. (1988), Raij (1991) e Borkert et al. (1993b) encontraram os mesmos sintomas em plantas de soja com deficiências severas de $K$.

Da mesma forma que para as classes de disponibilidade de K no solo, estabel eceram-se quatro faixas de teores de K no tecido foliar: muito baixo, quando menor que $9 \mathrm{~g} \mathrm{~kg}^{-1}$, com rendimentos inferiores a $60 \%$ do teto máximo; baixo, entre 9 e $12 \mathrm{~g} \mathrm{~kg}^{-1}$, com rendimentos médios entre 60 e $80 \%$ do teto máximo; médio, entre 12 e $14 \mathrm{~g} \mathrm{~kg}^{-1}$, com rendimentos entre 80 e $90 \%$ do teto máximo, e alto, quando acima de $14 \mathrm{~g} \mathrm{~kg}^{-1}$, com rendimentos superiores a $90 \%$ do teto máximo. O intervalo entre 14 e $19 \mathrm{~g} \mathrm{~kg}^{-1}$ de K-foliar foi definido como faixa de suficiência para al tas produtividades. Tais resultados, em termos gerais, estão bastante próximos às faixas de suficiência estabelecidas para a soja por Borkert et al. (1993b), no Estado do Paraná, e por Malavolta (1980) e Van Raij (1991), no Estado de São Paulo. 
Avaliando o efeito do $\mathrm{K}$ na absorção de Ca e de $\mathrm{Mg}$, que normalmente interagem com esse nutriente (Mascarenhas et al., 1988), verifica-se efeito depressivo desse na concentração de $\mathrm{Mg}$ na folha, enquanto a concentração de Ca não foi significativamenteafetada (Figura 4). Decréscimona rel ação K/Mg na fol ha indica menor absorção de $\mathrm{K}$ em função de sua menor disponibilidadenosolo (Figura 2). Esta foi compensada pela maior absorção de Mg pelas plantas (Figura 4), concor dando com a afirmação de Rosol em et al. (1992) de que a absorção de $\mathrm{Mg}$ pela planta é mais uma função da disponibilidade de K do que propriamente de Mg e confirma a interação negativa observada por diversos autores (Omar \& EI Kobbia, 1966; Mascarenhas et al., 1988; Rosolem et al., 1992).

A representação gráfica da figura 5 mostra que a relação Ca/Mg nas fol has aumentou linearmente com o teor de K-foliar, evidenciando a ocorrência de efeito substitutivo entre Mg eK, enquanto para o Ca parece mais um efeito de concentração ou de diluição, em função da redução ou aumento do volume de massa vegetal produzida.

Relações entre K e Mg na fol ha da ordem de 2,5 a 3,0 parecem as mais indicadas para a obtenção de al tas produtividades. As relações extremas de 0,36 e 3,84 entre K/M g, encontradas no presente estudo, podem indicar um possível desequilíbrio nutricional, com decréscimos no rendimento de grãos (Figura 6). Rosolem et al. (1992) obtiveram as maiores produtividades desoja quando a relação K/Mg na fol ha esteve entre 3,5 e6,5 eentre 4,5 e 7,5 para os cultivares Cristalina eIAC 8, respectivamente.

Os dados mostram que o mel hor entendimento das relações entre os vários nutrientes enriquece a diagnose fol iar e dá maior segurança às interpretações individuais (Raij, 1991).

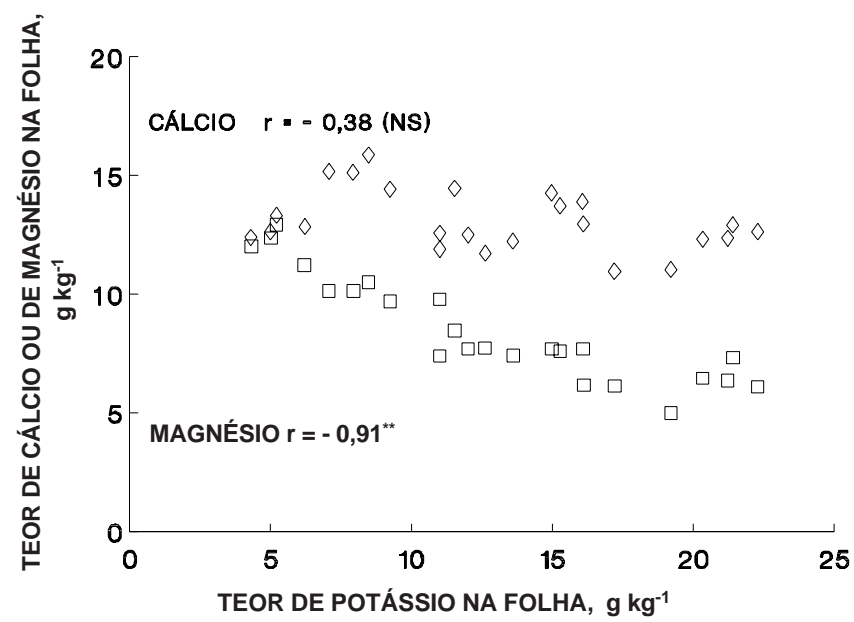

Figura 4. Relações entre os teores de cálcio ou de magnésio e os de potássio no tecido foliar de soja. Resultado de quatro safras. Média de três repetições.

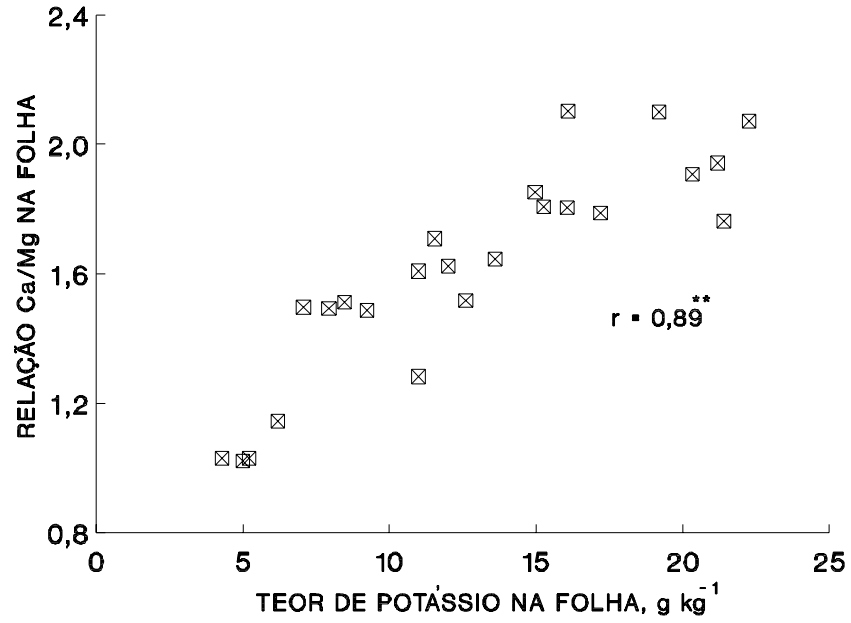

Figura 5. Relação entre $\mathrm{Ca} / \mathrm{Mg}$ e o teor de potássio no tecido foliar de soja. Resultado de quatro safras. Média de três repetições.

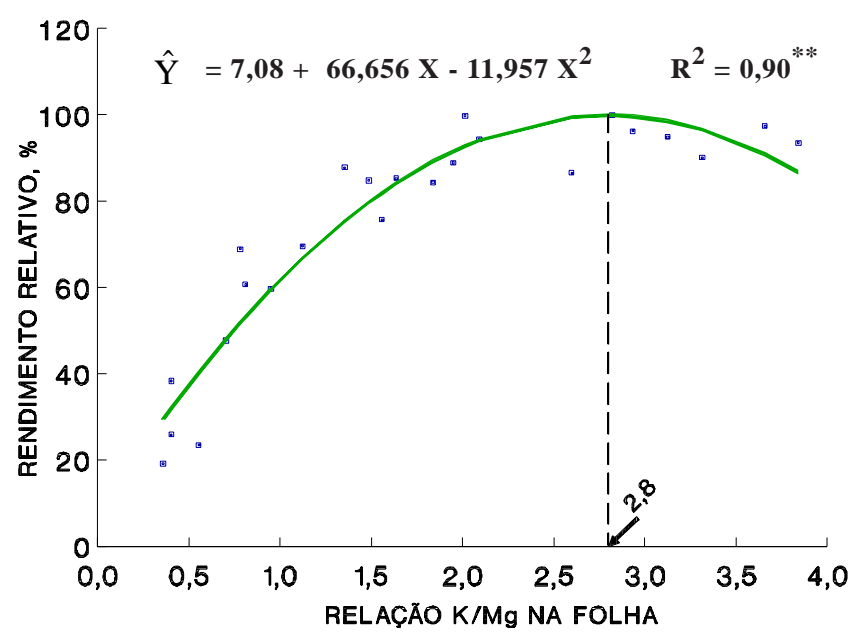

Figura 6. Rendimento relativo de soja em função da relação K/Mg no tecido foliar de soja. Resultado de quatro safras. Média de três repetições.

\section{CONCLUSÕES}

1. Existe relação entre os teores de $\mathrm{K}$ do solo (Mehlich-1) e da folha, bem como entre eles e a produção de grãos.

2. O teor de $\mathrm{K}$ considerado suficiente, para obter rendimentos de soja de $90 \%$ do teto máximo, situa-se em $14 \mathrm{~g} \mathrm{~kg}^{-1}$, na fol ha, e $63 \mathrm{mg} \mathrm{dm}^{-3}$, no solo.

3. As quatro classes de teores de $K$ no solo e no tecido foliar de soja definidas são: muito baixo, quando menor que $38 \mathrm{mg} \mathrm{dm}^{-3}$, no solo, e $9 \mathrm{~g} \mathrm{~kg}^{-1}$, na fol ha; baixo, quando entre 39 e $49 \mathrm{mg} \mathrm{dm}^{-3}$, no solo, e 9 e $12 \mathrm{~g} \mathrm{~kg}^{-1}$, na folha; médio, quando entre $50 \mathrm{e}$ $63 \mathrm{mg} \mathrm{dm}^{-3}$, no solo, e 12 e $14 \mathrm{~g} \mathrm{~kg}^{-1}$, na fol ha, e alto, quando acima de $63 \mathrm{mg} \mathrm{dm}^{-3}$, no solo, e acima de $14 \mathrm{~g} \mathrm{~kg}^{-1}$, na folha. 
4. O teor de Mg na folha da soja aumenta proporcionalmente com a diminuição dos teores deK.

\section{LITERATURA CITADA}

BATAGLIA, O.C. \& DECHEN, A.R. Critérios alternativos para diagnose foliar. In: SIMPÓSIO AVANÇADO DE QUÍMICA E FERTILIDADE DO SOLO, Piracicaba, 1986. Anais. Campinas, Fundação Cargill, 1986. p.115-136.

BEN, J .R. Resultados de pesquisa com potássio em soja no Rio Grande do Sul, Santa Catarina e Paraná. In: REUNIÃO DE PESQUISA DE SOJ A DA REGIÃO SUL, 9., Passo Fundo, 1981. Ata. Passo Fundo, EMBRAPA-CNPT, 1981. p.174.

BORKERT, C.M.; SFREDO, G.J . \& SILVA, D.N. Calibração de potássio trocável para soja em Latossolo Roxo distrófico. R. Bras. Ci. Solo, 17:223-226, 1993a.

BORKERT, C.M.; SILVA, D.N. \& SFREDO, G.J . Calibração de potássio nas fol has de soja em Latossolo Roxo distrófico. R. Bras. Ci. Solo, 17:227-230, 1993b.

COMISSÃO DE FERTILIDADE DO SOLO - RS/SC. Recomendações de adubação e de calagem para os estados do Rio Grande do Sul e deSanta Catarina. 3. ed. Passo Fundo, SBCS-Núcleo Regional Sul, 1995. 224p.

FERNANDES, D.M.; ROSSETO, C.A.V.; ISHIMURA, I. \& ROSOLEM, C.A. Nutrição da soja e formas de potássio no solo em função de cultivares e adubação potássica. R. Bras. Ci. Solo, 17:405-410, 1993.

MALAVOLTA, E. Elementos de nutrição mineral de plantas. São Paulo, Agronômica Ceres, 1980. 251p.

MALAVOLTA, E.; VITTI, G.C. \& OLIVEIRA, S.A. Avaliação do estado nutricional das plantas. Piracicaba, Associação Brasileira para Pesquisa da Potassa e do Fosfato, 1989. 201p.

MASCARENHAS, H.A.A.; NEPTUNE, A.M.L.; MURAOKA, T.; BULISANI, E.A. \& HIROCE, R. Absorção de nutrientes por cultivares de soja (Glicinemax (L.) Merril). R. Bras. Ci. Solo, 4:92-96, 1980

MASCARENHAS, H.A.A.; BULISANI, E.A.; MIRANDA, M.A.C.; PEREIRA, J.C.V.N.A. \& BRAGA, N.R. Deficiência de potássio em soja no Estado de São Paulo: melhor entendimento do problema e possíveis soluções. O Agronômico, 40:34-43, 1988.
MIELNICZUK, J. \& SELBACH, P.A. Capacidade de suprimento de potássio de seis solos do Rio Grande do Sul. R. Bras. Ci. Solo, 2:115-120, 1978.

OMAR, M.A. \& EL KOBBIA, T. Some observations on the interrelationships of potassium and magnesium. Soil Sci., 101:437-440, 1966.

RAIJ, B. van. Fertilidade do solo e adubação. Piracicaba, Ceres/ Associação Brasileira para Pesquisa da Potassa e do Fosfato, 1991. 343p.

ROSOLEM, C.A. Nutrição mineral e adubação da soja. 2.ed Piracicaba, Instituto de Potassa e do Fosfato, 1982 80p. (Boletim Técnico, 6)

ROSOLEM, C.A.; MACHADO, J .R. \& RIBEIRO, D.B.O. Formas de potássio no sol o e nutrição potássica da soja. R. Bras. Ci. Solo, 12:121-125, 1988.

ROSOLEM, C.A.; MACHADO, J R.R.; MAIA, I.G. \& NAKAGAWA, J . Respostas da soja ao magnésio do sol o. R. Bras. Ci. Solo, 16:4754, 1992.

SCHERER, E.E. Resposta da soja à adubação potássica em Latossolo Humico distrófico num período de doze anos. R. Bras. Ci. Solo, 22:49-55, 1998.

SCHERER, E.E.; J UCKSCH, I \& CASTILHOS, E.G. Avaliação da disponibilidadee do efeito residual do potássio no rendimento de grãos de soja. In: SOJ A - Resultados de Pesquisa obtidos em Santa Catarina no ano agrícola 1981/82. Chapecó, EMPASC-Estação Experimental de Chapecó, 1982. 15p.

SIQUEIRA, O.J .F. Nutrição e adubação potássica do trigo no Brasil. In: SIMPÓSIO SOBRE POTÁSSIO NA AGRICULTURA BRASILEIRA, Londrina, 1982. Anais, Piracicaba, Instituto da Potasssa e do Fosfato/I nstituto I nternacional da Potassa, 1982. p.449-486.

SOUZA, D.M.G. Calagem e adubação da soja nos cerrados. Planaltina, EMBRAPA-CPAC, 1984. 9p. (ComunicadoTécnico, 38)

TEDESCO, M.J . Extração simultânea de N, P, K, Ca eMg em tecido de plantas por digestão com $\mathrm{H}_{2} \mathrm{O}_{2}-\mathrm{H}_{2} \mathrm{SO}_{4}$. Porto Alegre, Universidade Federal do Rio Grande do Sul, 1982. 23p. (Informativo, 1/82)

VOLL, E. \& BAYS, I.A. Correção e adubação do sol o para a cultura da soja em Latosol Roxo distrófico. Pesq. Agrop. Bras., 11:9399, 1976. 